\title{
RNA sequencing of Xp11 translocation-associated cancers reveals novel gene fusions and distinctive clinicopathologic correlations
}

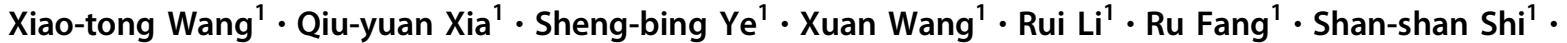

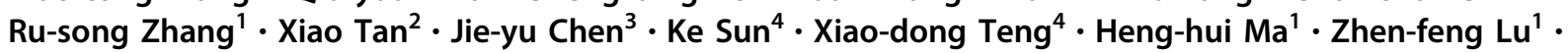 \\ Xiao-jun Zhou ${ }^{1} \cdot$ Qiu Rao ${ }^{1}$
}

Received: 1 January 2018 / Revised: 27 February 2018 / Accepted: 28 February 2018 / Published online: 30 April 2018

(c) United States \& Canadian Academy of Pathology 2018

\begin{abstract}
Both Xp11 translocation renal cell carcinomas and the corresponding mesenchymal neoplasms are characterized by a variety of gene fusions involving TFE3. It has been known that tumors with different gene fusions may have different clinicopathologic features; however, further in-depth investigations of subtyping Xp11 translocation-associated cancers are needed in order to explore more meaningful clinicopathologic correlations. A total of 22 unusual cases of Xp11 translocation-associated cancers were selected for the current study; 20 cases were further analyzed by RNA sequencing to explore their TFE3 gene fusion partners. RNA sequencing identified 17 of 20 cases (85\%) with TFE3-associated gene fusions, including 4 ASPSCR1/ASPL-TFE3, 3 PRCC-TFE3, 3 SFPQ/PSF-TFE3, 1 NONO-TFE3, 4 MED15-TFE3, 1 MATR3-TFE3, and 1 FUBP1-TFE3. The results have been verified by fusion fluorescence in situ hybridization (FISH) assays or reverse transcriptase polymerase chain reaction (RT-PCR). The remaining 2 cases with specific pathologic features highly suggestive of MED15-TFE3 renal cell carcinoma were identified by fusion FISH assay. We provide the detailed morphologic and immunophenotypic description of the MED15-TFE3 renal cell carcinomas, which frequently demonstrate extensively cystic architecture, similar to multilocular cystic renal neoplasm of low malignant potential, and expressed cathepsin $\mathrm{K}$ and melanotic biomarker Melan A. This is the first time to correlate the MED15-TFE3 renal cell carcinoma with specific clinicopathologic features. We also report the first case of the corresponding mesenchymal neoplasm with MED15TFE3 gene fusion. Additional novel TFE3 gene fusion partners, MATR3 and FUBP1, were identified. Cases with ASPSCR1TFE3, SFPQ-TFE3, PRCC-TFE3, and NONO-TFE3 gene fusion showed a wide variability in morphologic features, including invasive tubulopapillary pattern simulating collecting duct carcinoma, extensive calcification and ossification, and overlapping and high columnar cells with nuclear grooves mimicking tall cell variant of papillary thyroid carcinoma. Furthermore, we respectively evaluated the ability of TFE3 immunohistochemistry, TFE3 FISH, RT-PCR, and RNA sequencing to subclassify Xp11 translocation-associated cancers. In summary, our study expands the list of TFE3 gene fusion partners and the clinicopathologic features of Xp11 translocation-associated cancers, and highlights the importance of subtyping Xp11 translocation-associated cancers combining morphology, immunohistochemistry, and multiple molecular techniques.
\end{abstract}

These authors contributed equally: Xiao-tong Wang, Qiu-yuan Xia.

Electronic supplementary material The online version of this article (https://doi.org/10.1038/s41379-018-0051-5) contains supplementary material, which is available to authorized users.

Qiu Rao

raoqiu1103@126.com

1 Department of Pathology, Nanjing Jinling Hospital, Nanjing University School of Medicine, Nanjing, Jiangsu, China

2 Department of Pathology, Linyi People's Hospital,

\section{Introduction}

Xp11 translocation renal cell carcinomas are characterized by a variety of gene fusions involving TFE3, which is located on chromosome Xp11.2. Of known TFE3 gene

Linyi, Shandong, China

3 Department of Pathology, the Affiliated Drum Tower Hospital, Nanjing University Medical School, Nanjing, China

4 Department of Pathology, the First Affiliated Hospital, College of Medicine, Zhejiang University, Hangzhou, China 
fusion partners, ASPSCRI/ASPL, PRCC, and SFPQ/PSF are relatively common partners [1-4]. Recent advances help develop an improved understanding of clinicopathologic characteristics associated with NONO-TFE3 renal cell carcinoma and RBM10-TFE3 renal cell carcinoma [5-9]. The remaining DVL2, CLTC, PARP14, LUC7L3, KHSRP, and most recently reported partners, MEDI5, GRIPAP1, and $A R I D I B$, have only been demonstrated in case reports [1015]. These TFE3 gene fusion partners contribute strong promoters, resulting in overexpression of the fusion protein and strong nuclear TFE3 immunoreactivity, which is currently the most commonly used diagnostic technique for Xp11 translocation renal cell carcinoma [16, 17]. However, due to differences in fixation times, technical methods, and scoring systems, false-positive and false-negative results are quite frequent [18-23]. As a transcriptional target of the micropathalima-associated transcription factor family, cathepsin $\mathrm{K}$ also has been utilized in the diagnosis of MiT family translocation renal cell carcinomas, and it is differentially expressed dependent upon the fusion partner of the TFE3 gene [24, 25]. The TFE3 break-apart fluorescence in situ hybridization (FISH) assays on formalin-fixed paraffin-embedded tissue sections are now the preferred method for identification of TFE3 gene rearrangements, often resolving cases with equivocal TFE3 immunohistochemistry results $[18,26,27]$. However, when TFE3 gene rearrangements are caused by an inversion of chromosome $\mathrm{X}$, as in the NONO-TFE3, RBM10-TFE3, and GRIPAP1TFE3 gene fusions, it is difficult to detect these abnormalities by TFE3 break-apart FISH [5, 8, 9, 28-30]. Reverse transcriptase polymerase chain reaction (RT-PCR) can allow providing information as to the specific fusion partner of TFE3, but it requires high-quality RNA and only identifies known fusion variants.

Recently, an increasing number of TFE3 rearrangementassociated tumors have been reported, such as TFE3 rearrangement-associated perivascular epithelioid cell tumor, melanotic Xp11 translocation renal cancer, and melanotic Xp11 neoplasm [18, 31-43]. Although they are currently considered to have a morphology and phenotype (PAX8 negative, HMB45/Melan A positive, and S100 negative) most closely resembling that of perivascular epithelioid cell tumor [31, 32], Argani et al. noted differences between these neoplasms and perivascular epithelioid cell tumor including relatively younger age, absence of association with tuberous sclerosis, absence of TSC2 inactivation, absence of muscle marker expression, pure alveolar architecture, epithelioid morphology, and presence of TFE3 gene fusions. We and others have proposed the use of the name "Xp11 neoplasm with melanocytic differentiation" or "melanotic Xp11 neoplasm" rather than the originally proposed and widely used term "Xp11 translocation perivascular epithelioid cell tumor" to designate this unique entity
$[30,35,44] . S F P Q$ has been found to be a very common gene fusion partner in this entity, with rare cases demonstrating NONO-TFE3 and DVL2-TFE3 gene fusion [10, 30, 44]. As Xp11 translocation renal cell carcinoma and the corresponding mesenchymal neoplasms have different prognosis but may harbor an identical gene fusion, the differential diagnosis should be made between these two tumors, especially occurring in the kidney [44, 45]. The histologic features of purely epithelioid cells, melanin pigment, the specific immunoprofile (PAX8 negative, cathepsin $\mathrm{K}$ positive, Melan $\mathrm{A} / \mathrm{HMB} 45$ positive), and a more aggressive behavior distinguish them from Xp11 translocation renal cell carcinoma [7, 44, 45].

Although different gene fusions demonstrate a distinctive associated morphology, there can be morphologic overlap among different genotypes of Xp11 translocation-associated cancers. There are still some cases demonstrating unusual morphologies and failing to meet all morphologic criteria for either existing molecular subtype. Subtyping Xp11 translocation-associated cancers requires further molecular analysis. In this study, we applied RNA sequencing to explore the TFE3 gene fusion partners to 20 unusual cases of Xp11 translocation-associated cancers including 17 $\mathrm{Xp} 11$ translocation renal cell carcinomas and three mesenchymal counterparts, and the results were further supported by fusion FISH assays or RT-PCR. Another 2 cases with specific pathologic features highly suspicious for the MED15-TFE3 renal cell carcinoma were also included in the study, which were identified by fusion FISH assay. In addition, we further evaluated the ability of multiple methods to subclassify Xp11 translocation renal cell carcinoma respectively.

\section{Materials and methods}

\section{Case selection}

In this study, 22 cases representative of a spectrum of morphologies encountered in Xp11 translocation-associated cancers (Xp11 translocation renal cell carcinomas and the corresponding mesenchymal neoplasms) but without data as to the fusion partner subtype were retrieved from the diagnostic files and consultation cases in the Department of Pathology at Nanjing Jinling Hospital, Nanjing University School of Medicine, between 2006 and 2017. Although the morphology was not typical of the specific common genotype, these cases were all confirmed to harbor TFE3 gene rearrangements by TFE3 immunohistochemistry and/or TFE3 break-apart FISH assay. The deceptive histological patterns, distinctive immunoprofile, and available tissue for molecular studies were included for the selection criteria. In 20 cases, RNA sequencing was used to further characterize 
their TFE3 gene fusion partners. The remaining 2 cases (case 21 and 22) were not sent for fusion sequencing analysis but were identified because of their distinctive morphology and FISH results. Hematoxylin and eosin and immunohistochemical staining analyses were reviewed by experienced pathologists (R.Q. and X.Q.Y). The clinicopathological features and available follow-up information were obtained. This study was approved by the Institute Research Ethics Committee of Nanjing Jinling Hospital.

\section{Immunohistochemistry}

Tumor tissues were fixed in 10\% formalin and embedded in paraffin; 3- $\mu$ m-thick sections were immunohistochemically stained using antibodies against the following: TFE3 (SC5958, 1:300; Santa Cruz, CA), TFEB (ab2636, 1:300; Abcam, Cambridge, UK), cathepsin K (3F9, 1:300; Abcam), HMB45 (1:500; Dako, Glostrup, Denmark), Melan A (A103/M2-72, 1:100; NeoMarkers, Fremont, CA), PAX8 (4H7B3, 1:100; ProteinTech Group, Rosemont, IL), CD10 (56C6, 1:100; Novocastra, Milton keynes, UK), vimentin (V9, 1:200; Zymed), CK7 (OV-TL12/30, 1:300; Zymed, Grand Island, NY), RCC marker (PN-15, prediluted; MaxVision, Madison, AL), carbonic anhydrase IX (CA-IX) (ab1508, 1:1000; Abcam), and cytokeratin (AE1/ AE3, 1:150, Zymed).

Immunoreactions were performed using labeled streptavidin-biotin method and overnight incubation as previously described. Diaminobenzidine (3,3'-diaminobenzidine) was used for visualization. Immunoreactivity was evaluated in a semiquantitative manner to assess both labeling intensity and the percentage of immunopositive tumor cells, as described previously [44, 46]. For all antibodies, the resulting score was calculated by multiplying the staining intensity $(0=$ no staining, $1=$ mild staining, $2=$ moderate staining, and $3=$ strong staining) by the percentage of immunoreactive tumor cells ( 0 to 100). The immunostaining result was considered to be 0 or negative when the score was $<25 ; 1+$ or weak when the score was $26-100 ; 2+$ or moderate when the score was $101-200$; or 3 + or strong when the score was 201-300.

\section{RNA sequencing}

Twenty cases were analyzed by RNA sequencing. Total RNA from formalin-fixed paraffin-embedded samples was extracted after xylene deparaffinization using the RNeasy formalin-fixed paraffin-embedded kit (QIAGEN). Ribosomal RNA was depleted using RNase $\mathrm{H}$ followed by library preparation using the KAPA Stranded RNA-seq Kit with RiboErase (HMR) (KAPA Biosystems). Library concentration was performed using a KAPA Library Quantification Kit (KAPA Biosystems), and the library quality was accessed using an Agilent High Sensitivity DNA kit and Bioanalyzer 2100 (Agilent Technologies), followed by sequencing on Illumina HiSeq next-generation sequencing (NGS) platforms (Illumina) [47].

Three tools were applied for the detection of any potential TFE3 fusion of RNA-sequencing data. FusionCatcher (version 0.99.4e) was used with parameters (--BLAT aligner, otherwise, the default parameter was used) that apply the Bowtie aligner to perform both transcriptome and genome mapping and then used the BLAT aligner to further map unmapped reads and count fusion supporting evidence. The other two tools, Factera and Socrates (https:// github.com/jibsch/Socrates), were both executed using default parameters. Specifically, Socrates takes the modified BAM file, which converts the hard-clip in the original BAM file into a soft-clip to improve the fusion detection performance. The combined fusion results from all tools were manually reviewed on the Integrative Genomics Viewer for confirmation [47].

\section{RT-PCR and Sanger sequencing of the fusion transcript}

To validate the fusions identified with RNA sequencing, RT-PCR was performed as described previously [3, 48], using specific primers (Supplementary Table S1), followed by Sanger sequencing. For sequence analysis, the PCR products were purified using the Wizard PCR Preps Purification System (Promega, Madison, WI), and sequencing was performed using Big Dye Terminator and an ABI Basecaller (Applied Biosystems, Grand Island, NY).

\section{FISH}

FISH on interphase nuclei from paraffin-embedded 3- $\mu$ mthick sections was performed applying custom probes using bacterial artificial chromosomes (BAC). The BAC clones were selected using "CloneCentral human BAC Clone Locator" from Empire Genomics (http://www.empire genomics.com/CloneCentral/gene_search). Tumor tissues on the slides were deparaffinized and subjected to heat pretreatment (pressure cooking for $10 \mathrm{~min}$ at full pressure) in distilled water and then digested by incubation with $0.25 \%$ pepsin (Sigma, Taufkirchen, Germany) and $0.01 \mathrm{M}$ $\mathrm{HCl}$ for $15 \mathrm{~min}$ at $37^{\circ} \mathrm{C}$. After rinsing twice in $2 \mathrm{x} \mathrm{SSC}$ for $5 \mathrm{~min}$, the tissues were dehydrated by immersing the slides in 70,85 , and $100 \%$ ethanol for 1 min each at room temperature and then air dried. The probes were diluted in tDenHyb 2 (Insitus, Albuquerque, NM, USA) at a ratio of 1:25. The slides containing the tissue DNA probes $(10 \mu \mathrm{l}$ per slide) were co-denatured in an in situ thermocycler (System 1000, Perkin Elmer, Waltham, Massachusetts, USA) at $83{ }^{\circ} \mathrm{C}$ for $12 \mathrm{~min}$, annealed at $37^{\circ} \mathrm{C}$, and 


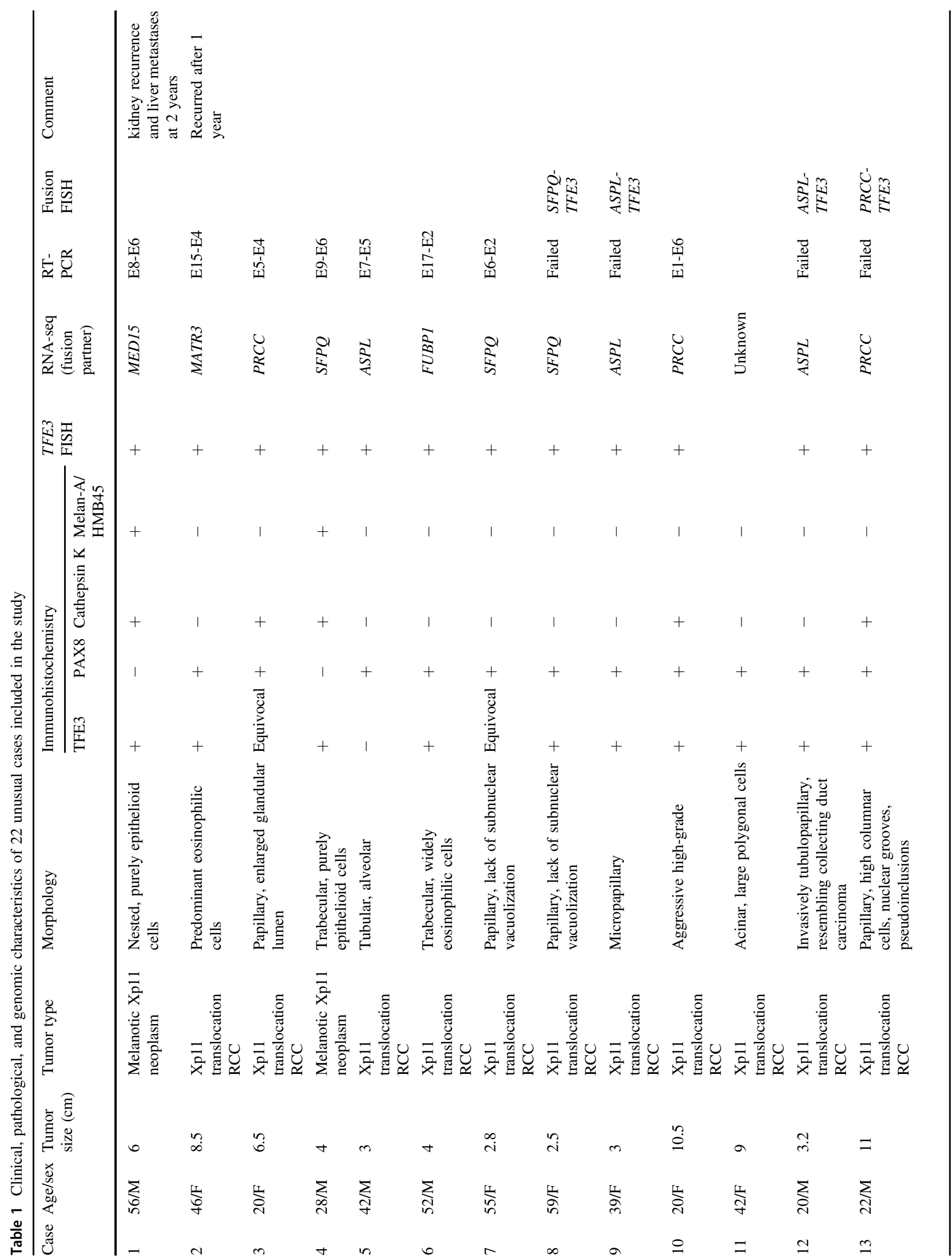




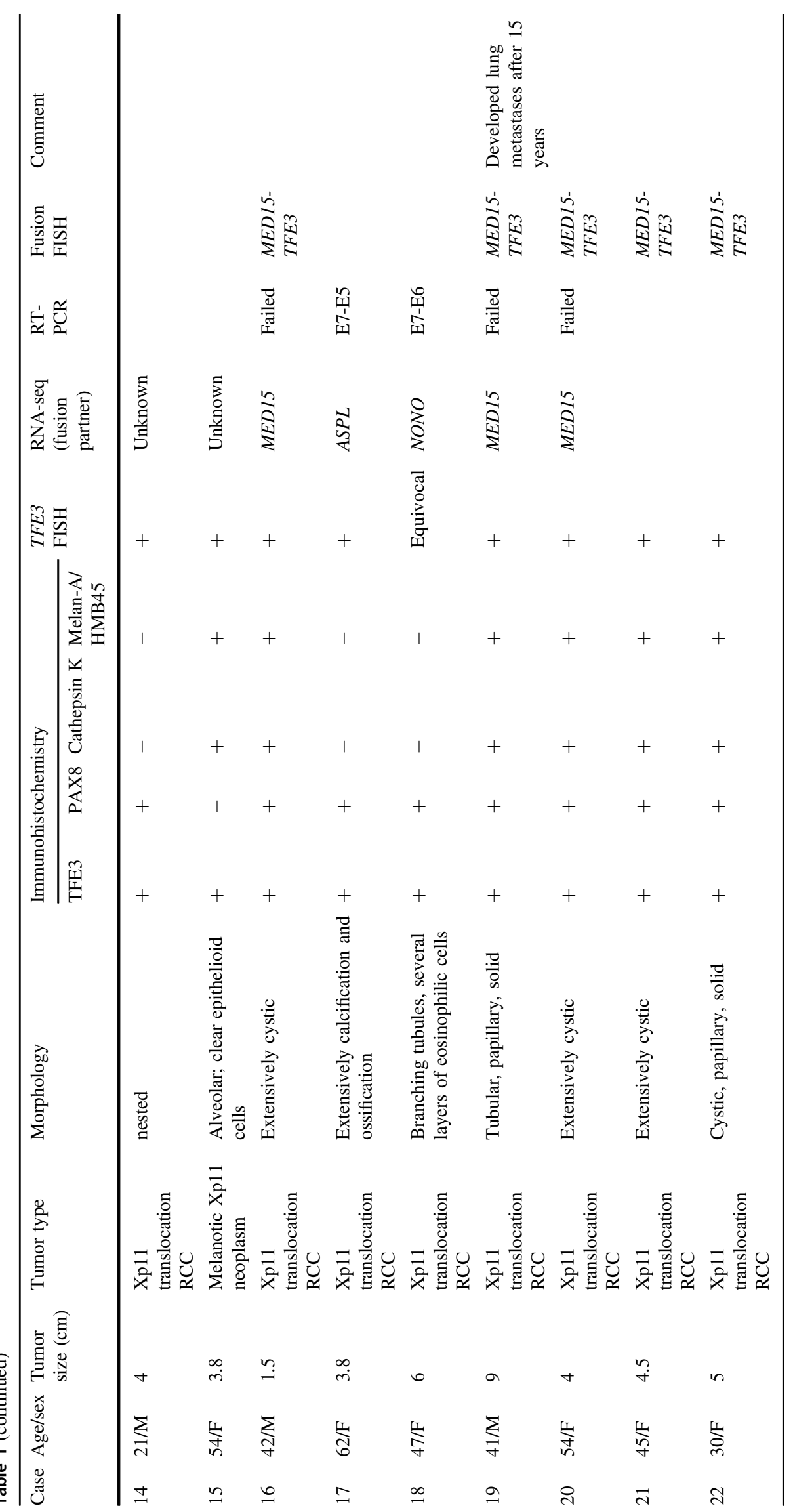




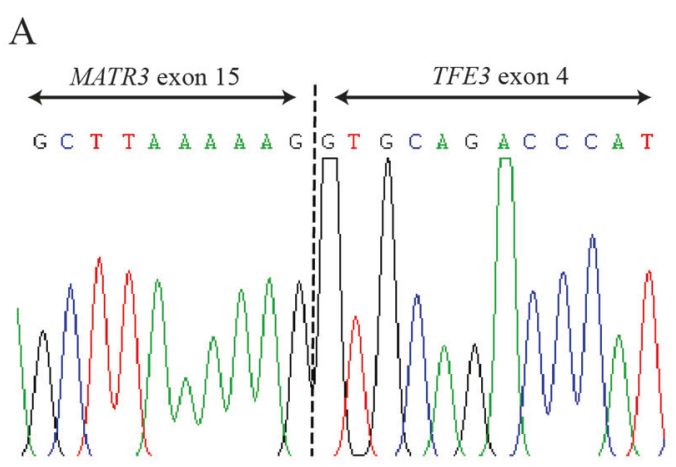

Case 2

C

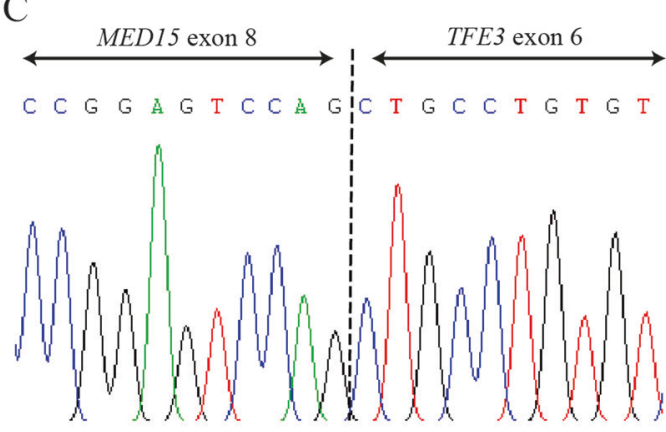

Case 1

$\mathrm{E}$

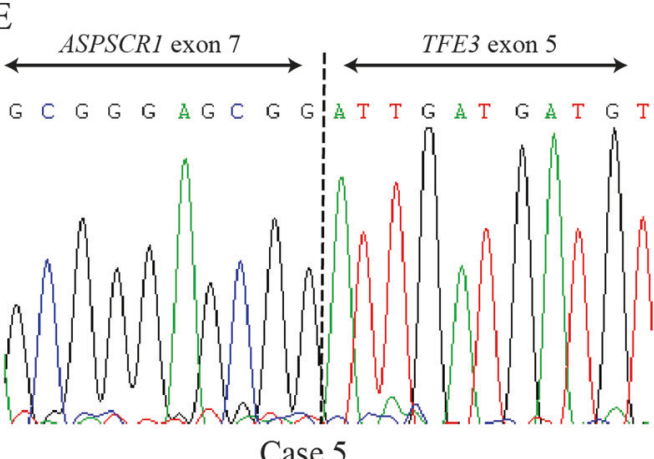

G

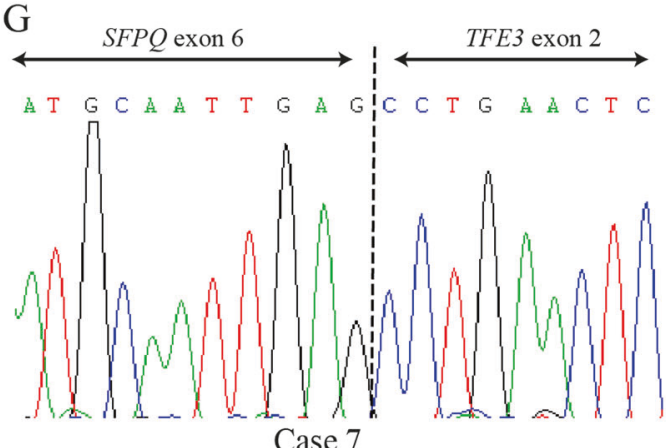

Fig. 1 Confirmation of fusion transcripts by RT-PCR. Two novel fusion transcripts: a MATR 3 exon 15 fused with TFE3 exon 4 (case 2); b FUBP1 exon 17 fused with TFE3 exon 2 (case 6). c Fusion of $M E D 15$ exon 8 with TFE3 exon 6 (case 1); d 5'MED15 probe (red, centromeric) fused to the $3^{\prime} T F E 3$ probe (green, telomeric) by fusion
B

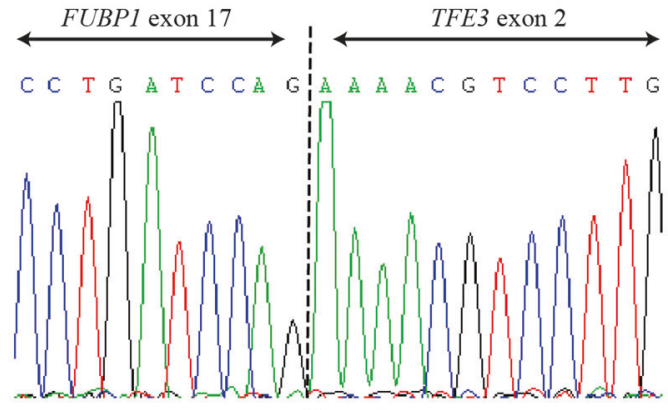

Case 6

$\mathrm{D}$

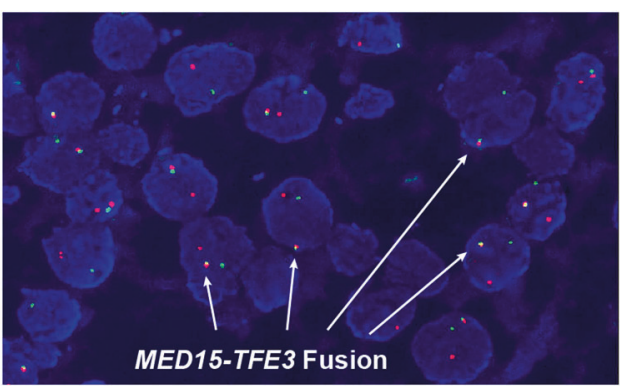

Case 16

F

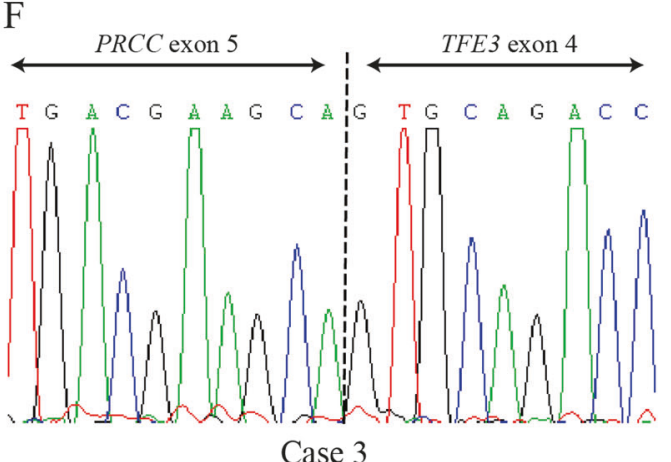

$\mathrm{H}$

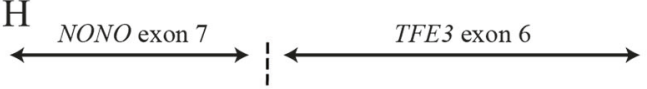

$C C$ T G A T G C G G C T G C C T G T G T CA G

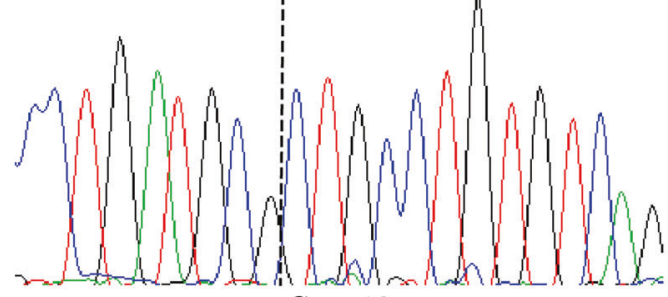

Case 18

FISH assay. e Fusion of ASPSCR1 exon 7 with TFE3 exon 5. f A novel fusion type $P R C C$ exon 5 fused with TFE3 exon 4 (case 3). $\mathbf{g}$ Fusion of $S F P Q$ exon 6 with TFE3 exon 2 (case 7). h Fusion of $N O N O$ exon 7 with TFE3 exon 6 (case 18) 


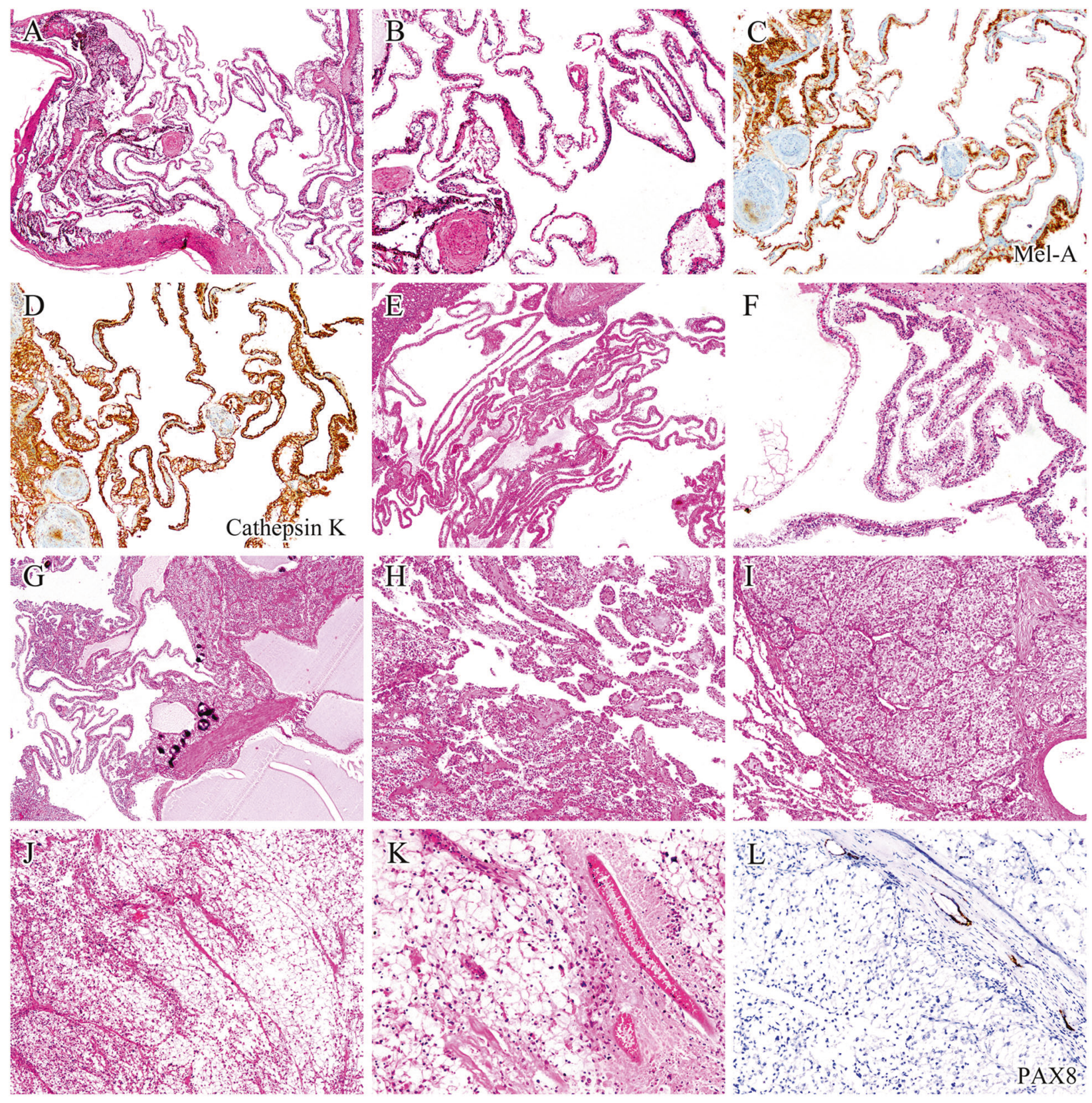

Fig. 2 Xp11 translocation-associated cancers involving MED15-TFE3 gene fusion. a, b Case 20 showed an extensively cystic architecture, featuring thin fibrous septa of cells with abundant clear to granular cytoplasm and closely mimicking multilocular cystic renal neoplasm of low malignant potential. The tumor cells showed diffuse cytoplasmic labeling for cathepsin K (c) and Melan-A (d). Case $21(\mathbf{e})$ and case 16 (f) were also extensively cystic, reminiscent of multilocular

hybridized in a humidified chamber at $37^{\circ} \mathrm{C}$ overnight. After post-hybridization washing in $0.4 \times \operatorname{SSC}\left(70^{\circ} \mathrm{C}\right.$ for 2 $\mathrm{min}$ ) and $2 \times \mathrm{SSC}$ (room temperature for $2 \mathrm{~min}$ ), a coverslip was added to the slides with $10 \mathrm{ml}$ of 4,6-diamino-2-phenylindole for counterstaining.

A split probe assay to identify TFE3 gene rearrangement has been performed at the time of diagnosis. A fused or cystic renal neoplasm of low malignant potential. g, h Case 22 demonstrated distinct cystic areas, mixed with solid and papillary areas. i Case 19 metastasized to the lung showing a solid nested pattern. $\mathbf{j}$, k Case 1 demonstrated a nested architecture separated by a delicate vascular network featuring purely epithelioid cells with focal necrosis. Immunohistochemistry for PAX8 (1) was negative

closely approximated green-red signal pattern was interpreted as a normal result, whereas a split signal pattern indicated the presence of a TFE3 translocation. The signals were considered to be split when the green and red signals were separated by a distance $\geq 2$ signal diameters. In addition, validation of genes that identified as potential fusion partners in the RNA-sequencing experiment but not 
confirmed by RT-PCR was performed by fusion probe assays, including SFPQ-TFE3, ASPSCR1-TFE3, PRCCTFE3, and MED15-TFE3 gene fusion probes. The frequent fusion probes for FISH evaluation have been described previously [44, 49]. For the MED15-TFE3 fusion assay, the BAC clone RP11-586I18, located centromeric to the MED15 gene locus, was labeled with 5-fluorescein-dUTP. The BAC clone RP11-416B14, located telomeric to the TFE3 gene locus, was labeled with 5-ROX-dUTP. A colocalized signal represented a fusion between TFE3 and the potential fusion partner.

For each case, a minimum of 100 tumor nuclei were examined for probe signals by fluorescence microscopy at $\times 1000$ magnification. To avoid false-positive interpretations resulting from nuclear truncation, only nonoverlapping tumor nuclei were evaluated. On the basis of the generally accepted guidelines used by all other commercially available break-apart FISH assays and developed TFE3 breakapart FISH assays, a positive score was reported when $>10 \%$ of the nuclei in the tumor tissue showed evidence of TFE3 gene rearrangement or potential gene fusion.

\section{Results}

\section{Fusion transcripts by RNA sequencing}

Table 1 shows the clinicopathologic features for the 22 cases. All but two (case 21 and 22) of these neoplasms with known TFE3 gene rearrangements demonstrated by TFE3 immunohistochemistry and TFE3 split FISH assay were analyzed by RNA sequencing for fusion partners (Supplementary material). Gene fusions were successfully detected in 17 of 20 cases $(85 \%)$, of which $11(65 \%, 11 / 17)$ showed relatively common gene fusions, involving ASPSCRI/ ASPL-TFE3 gene fusion (4 cases), PRCC-TFE3 gene fusion (3 cases), SFPQ/PSF-TFE3 gene fusion (3 cases), and NONO-TFE3 gene fusion (1 case). Four cases demonstrated a rare TFE3-associated gene fusion, MED15-TFE3, which was only identified in one case most recently [14]. Additionally, two novel TFE3-associated gene fusions were identified including MATR3-TFE3 (1 case) and FUBPITFE3 gene fusion (1 case). These gene fusions were validated by RT-PCR or FISH assay in all of the 17 cases. No gene partner was identified in 3 cases by RNA sequencing. Case 21 and 22 that we initially suspected to be MED15TFE3 renal cell carcinoma based on specific morphological and immunophenotypic features proved to have MED15TFE3 fusion signals by fusion FISH. Histologic appearance varied significantly among these cases.

\section{First detailed morphologic and immunophenotypic description of TFE3-rearranged cancers involving MED15-TFE3 gene fusion}

MED15-TFE3 gene fusion was identified by RNA sequencing in 4 cases (cases 1, 16, 19, and 20) and by fusion FISH probe in 2 cases (case 21 and 22). These comprised 5 cases of Xp11 translocation renal cell carcinoma (cases 16, 19, 20, 21, and 22) and 1 case of melanotic Xp11 neoplasm (case 1). On the basis of this result, RTPCR further confirmed fusion transcript in case 1 showing MED15 exon 8 fused to TFE3 exon 6 (Fig. 1c). The other 3 cases (cases 16, 19, and 20) were positive by the MED15TFE3 fusion probe FISH assay (Fig. 1d).

These five renal cell carcinomas (cases 16, 19, 20, 21, and 22), harboring a MED15-TFE3 gene fusion, affected two male and three female individuals (mean age 42.4 years, median 42 years). Four cases were free of disease with 2-13 months of follow-up, whereas case 19 had developed lung metastases after 15 years. Three of these cases (cases 16, 20, and 21) demonstrated an extensively cystic architecture featuring thin fibrous septa of variably prominent clusters of cells with abundant clear to granular cytoplasm, uniform round nuclei, and small inconspicuous nucleoli, closely mimicking multilocular cystic renal neoplasm of low malignant potential (Fig. 2a, b, e, f). Case 22 demonstrated distinct cystic areas, merged with papillary and solid structures lined by cells with clear to granular cytoplasm (Fig. 2g, h). The primary renal cell carcinoma of case 19 was composed of epithelioid cells with clear to eosinophilic cytoplasm arranged in acinar, tubular, and papillary formations. Hematoxylin and eosin sections of case 19 involving lung showed a solid nested pattern (Fig. 2i). A large nonstructured necrotic zone was readily identifiable. None of these cases demonstrated melanin pigment. In addition to diffuse, strong TFE 3 and PAX8 labeling, all 5 cases labeled diffusely for melanocytic markers cathepsin K and Melan A (Fig. 2c, d).

Case 1 was a 56-year-old man with a right renal mass measuring $6 \mathrm{~cm}$, and then developed kidney recurrence and liver metastases after 2 years. The morphology was that of a nested architecture separated by a delicate vascular network featuring purely epithelioid cells with clear to finely granular eosinophilic cytoplasm, typical of melanotic Xp11 neoplasm, although melanin pigment was unidentifiable. Nuclear atypia, defined nucleoli, and necrosis were also observed, suggesting a relatively more aggressive behavior. This case was diffusely immunoreactive for TFE3 and melanocytic markers cathepsin $\mathrm{K}$ and Melan A, but negative for PAX8 (Fig. 2j, k, 1). 
Fig. $3 \mathrm{Xp} 11$ translocation renal cell carcinomas with novel fusion partners, MATR 3 and $F U B P 1 . \mathbf{a}, \mathbf{b}, \mathbf{c}$ Case 2 demonstrated predominant eosinophilic cells with voluminous and granular cytoplasm, and prominent nucleoli. d, e, f Case 6 was composed of trabecular and solid areas, with psammoma bodies, focal hemorrhagic and necrotic changes
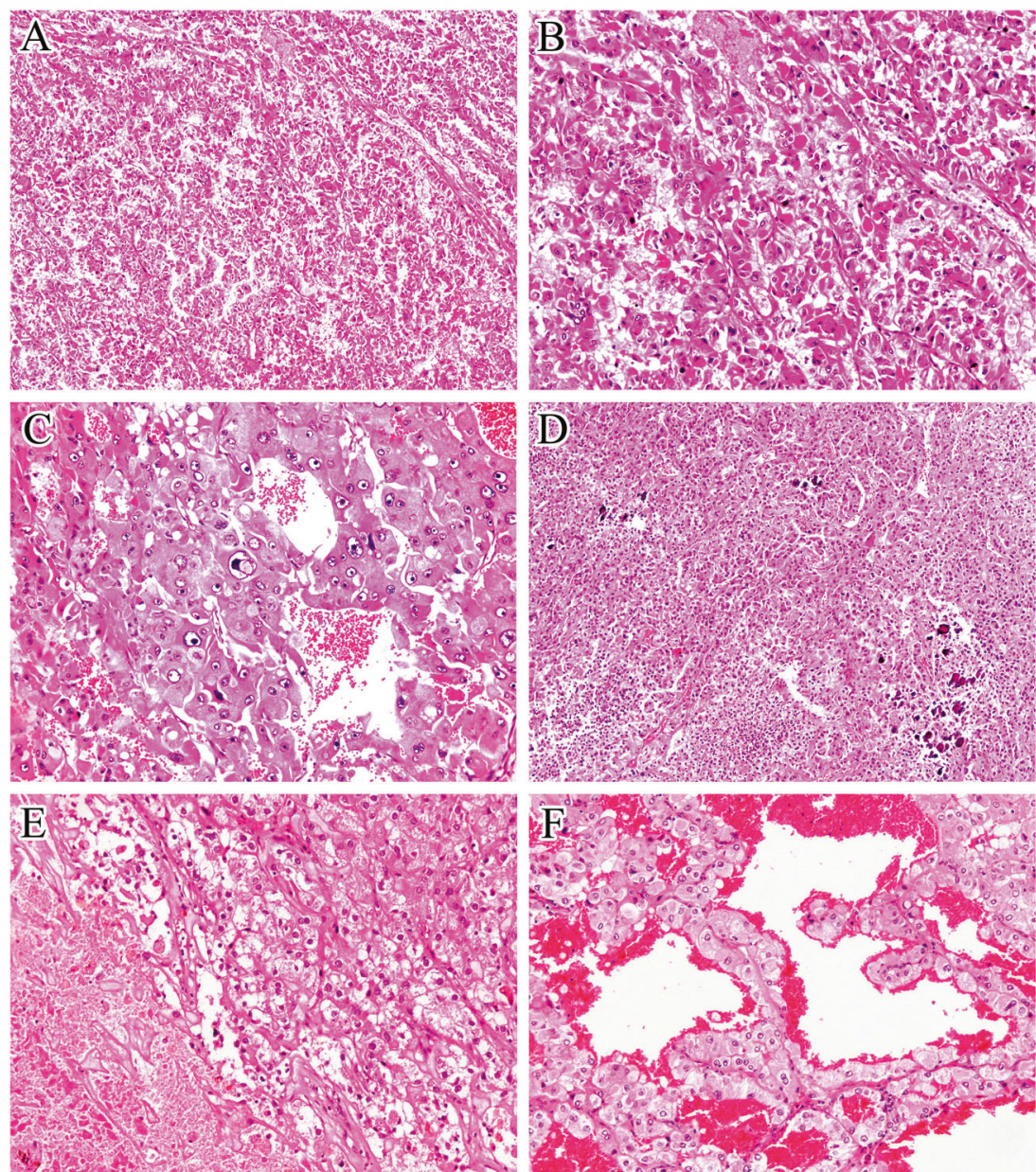

\section{Novel MATR3-TFE3 and FUBP1-TFE3 gene fusions identified in Xp11 translocation renal cell carcinoma}

RNA sequencing followed by fusion gene analysis identified a novel fusion of MATR3 and TFE3 in case 2, which was further confirmed by RT-PCR showing exon 15 of MATR3 (matrin 3, 5q31.2) fused to exon 4 of TFE3 (Fig. 1a). This neoplasm was an $8.5 \mathrm{~cm}$ right renal tumor in a 46-year-old woman. This tumor showed predominance of eosinophilic cells with voluminous, granular cytoplasm and prominent nucleoli, arranged in a solid sheet-like pattern with focal tubular areas. By immunohistochemistry, this tumor was positive for TFE3 and PAX8, but negative for cathepsin $\mathrm{K}$ and Melan $\mathrm{A} / \mathrm{HMB} 45$. This patient recurred after 1 year (Fig. 3a, b, c).

An additionally novel FUBPI-TFE3 gene fusion was identified in 1 case (case 6) by RNA-sequencing method. FUBP1 (far upstream element binding protein 1) is located on chromosome 1 (1p31.1). Experimental validation by RTPCR confirmed a transcript composed of FUBP1 exon 17 fused to TFE3 exon 2 (Fig. 1b). The patient was a 52-yearold male with a 4-cm right kidney mass. Microscopically, the tumor was composed of trabecular and solid areas, with focal hemorrhagic and necrotic changes. Tumor cells were widely eosinophilic specifically and sometimes clear. Psammoma bodies were also noted. Immunohistochemistry analysis showed strong and diffuse expression of TFE3 and PAX8, and no expression of the melanocytic markers cathepsin K and Melan A/HMB45. (Fig. 3d, e, f)

\section{Common known TFE3 molecular subtype with unusual morphology}

RNA sequencing on four renal cell carcinomas (cases 5, 9, 12, and 17) identified ASPSCR1/ASPL-TFE3 gene fusion. RT-PCR demonstrated that the gene fusion points were between exon 7 of ASPSCR1 and exon 5 of TFE3 in both case 5 (Fig. 1e) and case 17. Fusion FISH assay succeeded to detect the fusion gene in other 2 cases. These cases affected two females and two males, ranging from 20 to 62 years (mean, 40.8 years; median, 29.5 years). Microscopically, in all 4 cases, a distinct branching, papillary structure composed of large tumor cells without cellular cohesion, as would be expected of ASPSCRI/ASPL-TFE3 renal cell carcinoma, is lacking. The morphologic pattern of case 5 was characterized by tubular to alveolar structures 

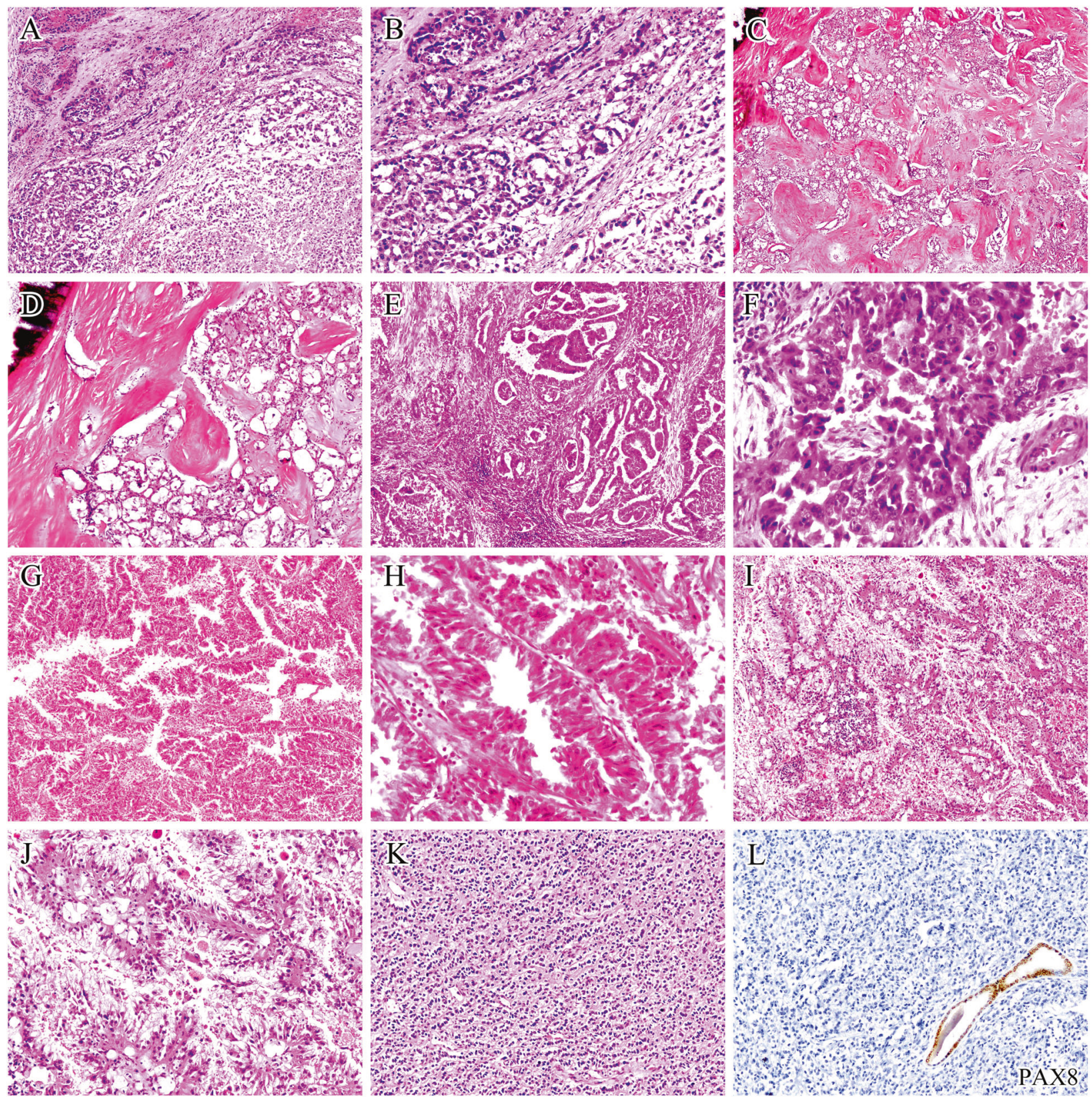

Fig. 4 Unusual morphologic appearance of common known TFE3 molecular subtype. a-d ASPSCR 1-TFE3 renal cell carcinoma. Case 12 (a, b) demonstrated an infiltrative ductal pattern with desmoplastic response and hobnail cells are commonly found, resembling collecting duct carcinoma. Case 17 (c, d) was composed of extensive sclerosis, hyalinization, calcification, and ossification with clear to eosinophilic cells. e-h PRCC-TFE3 renal cell carcinoma. Case 10 (e, f) demonstrated more aggressive morphology, infiltrative growth pattern into the surrounding parenchyma, high-grade atypia, and prominent

nucleoli. Case $13(\mathbf{g}, \mathbf{h})$ demonstrated predominant papillary structure lined by high columnar and overlapping cells with grooves, reminiscent of tall cell variant of papillary thyroid carcinoma. NONO-TFE3 renal cell carcinoma. Case 18 (i, j) demonstrated branching tubules and papillary structure, somewhat like ASPSCR1-TFE3 renal cell carcinoma. Melanocytic mesenchymal neoplasm with $S F P Q$-TFE3 gene fusion. Case $4(\mathbf{k})$ demonstrated trabeculae and cords of epithelioid clear cells with small round nuclei. Immunohistochemistry for PAX8 (I) was negative

with intervening hyalinized fibrous septae, populated by neoplastic cells with eosinophilic granular cytoplasm. Case 9 showed predominantly micropapillary structures lined by eosinophilic cells; a few of psammoma bodies were present as well. Case 12 morphologically closely resembled collecting duct carcinoma, showing an invasive tubulopapillary pattern with desmoplastic response (Fig. 4a). Hobnail cells were commonly found (Fig. 4b). Case 17 demonstrated extensive sclerosis, hyalinization, calcification, and ossification characterized by metaplastic bone formation, and was contained of clear to eosinophilic cells with small irregular nuclei and inconspicuous nucleoli (Fig. 4c, d). Three cases 
(cases 9, 12, and 17) showed strong positivity of the TFE3 immunohistochemistry; however, case 5 was negative. All 4 cases were typically PAX8 positive and cathepsin $\mathrm{K}$ negative.

A total of three renal cell carcinomas (cases 3,10, and 13) demonstrated PRCC-TFE3 gene fusion by RNA sequencing. Sequencing of the PCR products revealed that the fusion gene transcript consisted of a novel fusion type $P R C C$ exon 5 fused with TFE3 exon 4 in case 3 (Fig. 1f), and $P R C C$ exon 1 fused with TFE3 exon 6 in case 10. Fusion FISH assay confirmed PRCC-TFE3 gene fusion in case 13. These cases affected two females and one male, ranging from 20 to 22 years (mean, 21 years; median, 20 years). Case 3 showed regions of papillary architecture and areas with enlarged glandular lumen, both lined by clear to eosinophilic cells with small irregular nuclei; relatively extensive psammoma bodies could be seen. Case 10 demonstrated more aggressive morphology, infiltrative growth pattern into the surrounding parenchyma, highgrade atypia, prominent nucleoli, and necrosis (Fig. 4e, f). Case 13 had predominant papillary structure characterized by overlapping and high columnar cells with nuclear grooves, a feature typically seen in tall cell variant of papillary thyroid carcinoma (Fig. 4g, h). Nuclear TFE3 staining was moderate or strong in 2 cases, but case 3 showed an equivocal pattern. PAX8 and cathepsin $\mathrm{K}$ were strongly and diffusely expressed in every case.

There were two renal cell carcinomas (cases 7 and 8) and 1 case of melanotic Xp11 neoplasm (case 4) occurred in kidney harboring SFPQ/PSF-TFE3 gene fusion. Sequencing of the PCR products revealed that the fusion gene transcript consisted of $S F P Q$ exon 9 fused with TFE3 exon 6 in case 4, and SFPQ exon 6 fused with TFE3 exon 2 in case 7 (Fig. 1g). The fusion gene of case 8 was further validated by fusion FISH probe. Case 4 was a 28 -year-old male, characterized by trabecular and cords of purely epithelioid cells with predominantly clear cytoplasm, small round nuclei, and inconspicuous nucleoli (Fig. 4k). By immunohistochemistry, this neoplasm was strong positive for TFE3, cathepsin $\mathrm{K}$, and HMB45, but not for PAX8 (Fig. 41). Tumors from cases 7 and 8 were nearly identical in histologic appearance, featuring papillary structure lined by eosinophilic and occasionally clear cells. Subnuclear vacuolization, a pattern that was characteristic of $S F P Q$ $T F E 3$ renal cell carcinoma, was not identified in two $S F P Q$ TFE3 renal cell carcinomas. Case 8 expressed TFE3 immunohistochemistry definitely, but case 7 was equivocal. These two cases were moderate to strong positive for PAX8, but negative for cathepsin K and Melan-A/HMB45.

Case 18 was 47 -year-old, found to have a $6.0-\mathrm{cm}$ right upper pole renal mass. To establish the initial diagnosis, the TFE3 break-apart FISH was performed but the result was not easily interpretable. The signals were separated by a distance of nearly or less than 1 signal diameters, suspicious of NONO-TFE3 or RBM10-TFE3 molecular subtype. Given strongly positive staining for TFE3, RNA sequencing was used to further describe the molecular abnormality and demonstrated NONO-TFE3 gene fusion in this case. RTPCR then confirmed this gene fusion showing exon 7 of NONO fused to exon 6 of TFE3 (Fig. 1h). The predominant pattern of this case was that of branching tubules and papillary structure with hyalinized fibrovascular cores lined by several layers of eosinophilic cells with small, irregular nuclei lacking of cellular cohesion focally, somewhat like ASPSCR1-TFE3 renal cell carcinoma (Fig. 4i, j). Subnuclear vacuolization, also characteristic of $N O N O-T F E 3$ renal cell carcinoma, was not observed. This case was positive for PAX8, and negative for both cathepsin $\mathrm{K}$ and Melan A/HMB45 by immunohistochemistry.

\section{Three TFE3-rearranged cancers with unknown fusion partner}

These included two Xp11 translocation renal cell carcinomas (cases 11 and 14) and 1 case of melanotic Xp11 neoplasm located in the adrenal gland (case 15). The clinicopathologic features are summarized in Table 1. Case 11 showed a combination of acinar, tubular to papillary architecture composed of large polygonal cells with granular eosinophilic cytoplasm and prominent nucleoli. Massive necrosis and a few psammoma bodies were present. Case 14 showed nested solid architecture dominated by clear to eosinophilic cells with inconspicuous nucleoli. Case 15 showed purely clear cell epithelioid morphology and nested to alveolar architecture, with evident melanin pigment. Immunohistochemistry of TFE3 revealed strong, diffuse nuclear immunoreactivity in all 3 cases. Case 11 and case 14 were positive for PAX8 but not for cathepsin $\mathrm{K}$ and Melan-A/HMB45. Case 15 had an opposite immunohistochemical profile, being positive for cathepsin $\mathrm{K}$ and Melan A but not for PAX8.

\section{Discussion}

In this study, we performed a comprehensive genomic characterization by applying combined molecular methodologies, RNA sequencing, FISH, and RT-PCR, to define TFE3 fusion partners of $\mathrm{Xp} 11$ translocation-associated cancers, as well as to establish possible correlations between TFE3 molecular subtype and the distinct pathologic features. The cases were initially screened for TFE3 gene rearrangement by TFE3 break-apart FISH assay, followed by RNA sequencing to further characterize the fusion transcripts. We also corroborated the results using fusion FISH assays and RT-PCR. 
Our study reveals important findings. We identified five cases of Xp11 translocation renal cell carcinoma with MED15-TFE3 gene fusion, and first described the special morphology and immunophenotype of this entity. As known, only a single case of MED15-TFE3 renal cell carcinoma has been reported previously, but the details of the clinical, morphologic, immunohistochemical features and images of this genotype were not presented [14]. In our study, we found that certain morphologic features could be linked to the MED15-TFE3 renal cell carcinoma, which frequently demonstrated extensively cystic architecture, similar to multilocular cystic renal neoplasm of low malignant potential. We also note that a total of seven Xp11 translocation renal cell carcinomas with unknown fusion partner have been reported to demonstrate extensively cystic architecture but only 4 cases were provided their immunohistochemical features showing strong labeling for cathepsin $\mathrm{K}$ and/or Melan A [7, 18, 26, 50]. It is possible that MED15-TFE3 renal cell carcinomas are associated with melanotic differentiation, as cathepsin $\mathrm{K}$ and melanotic biomarker Melan A expression were found in all 5 cases in our study and 4 potential cases reported by Rao et al. [18]. and Argani et al. [7, 26]. Perhaps, the presence of MED15TFE3 gene fusion in Xp11 translocation renal cell carcinoma can be suspected due to its special morphologic and immunohistochemical features. As noted that MED15-TFE3 renal cell carcinoma is morphologically overlapping with multilocular cystic renal neoplasm of low malignant potential but the latter is a borderline tumor, distinguishing these two tumors is of major importance. In addition, we also reported the first case of melanotic Xp11 neoplasm harboring identical MED15-TFE3 gene fusion, which presented as malignant biological behavior with kidney recurrence and liver metastases at 2 years. This gene fusion has not been previously reported in the melanotic Xp11 neoplasms until now. Although both of MED15-TFE3 renal cell carcinoma and its mesenchymal counterpart express cathepsin K and Melan A, the distinct morphology (purely epithelioid morphology, melanin pigment) and immunohistochemical profile (PAX8 negative) are the clues to the diagnosis of melanotic Xp11 neoplasms.

Additionally, we identified four ASPSCRI/ASPL-TFE3, 3 SFPQ/PSF-TFE3, 3 PRCC-TFE3, and 1 NONO-TFE 3 in this study. The first three gene fusions emerge as relatively prevalent genetic events among Xp11 translocationassociated cancers. Although NONO-TFE3 gene fusion is rare, recent advances help develop an improved understanding of clinicopathologic characteristics associated with this molecular subtype [5, 7]. The specific molecular subtype of Xp11 translocation renal cell carcinomas may have its own dominant morphologies. ASPSCRI-TFE3 gene fusion is associated with voluminous clear cytoplasm, discrete cell borders, an alveolar or papillary growth pattern, and psammoma bodies [51], whereas PRCC-TFE3 renal cell carcinoma tends to possess a nested growth pattern, smaller cells with less abundant cytoplasm, and fewer calcifications [17, 52]. NONO-TFE3 renal cell carcinoma frequently demonstrates a biphasic pattern that contains sheets of epithelial cells and glandular/tubular or papillary architecture, lined with high columnar cells and the nuclei toward the luminal surface leading to the appearance of secretory endometrioid subnuclear vacuolization [5, 7]. Subnuclear vacuolization was also characteristic of $S F P Q$ TFE3 renal cell carcinoma [7, 45]. However, cases of prevalent TFE3 molecular subtypes submitted in this study showed a wide variability in morphologic features, such as invasive tubulopapillary pattern reminiscent of collecting duct carcinoma, extensive calcification and ossification, and overlapping and high columnar cells with nuclear grooves mimicking tall cell variant of papillary thyroid carcinoma. Furthermore, we noted considerable morphological heterogeneity in these cases despite an identical gene fusion. Our study expands the morphologic spectrum of the existing molecular subtypes of Xp11 translocation-associated cancers. Given the unusual morphologic appearances observed in this study, these cases could not confidently be subclassified into any of the existing molecular subtypes of Xp11 translocation-associated cancers. As such, we applied RNA sequencing to establish their TFE3 fusion gene partners, interestingly more than half of the cases $(65 \%, 11 / 17)$ still demonstrating the commonly identified TFE3 gene fusion partners. Our study findings indicate that Xp11 translocation-associated cancers confirmed by split TFE3 FISH assay could be further worked up by conventional molecular techniques, such as fusion FISH assay and RTPCR, to exclude common molecular subtypes, even if the morphologic features are not typical.

We also discovered two novel TFE3 fusion partners, MATR3 and FUBP1, which expanded the molecular spectrum of Xp11 translocation renal cell carcinomas. These two gene fusions were confirmed by RT-PCR demonstrating the fusion of MATR3 exon 15 with TFE3 exon 4, and the fusion of FUBP1 exon 17 with TFE3 exon 2. MATR3, which encodes the nuclear matrix protein matrin 3 , is involved in multiple nuclear processes [53-55]. Interestingly, MATR 3 has been reported as a cause of the neurodegenerative disease familial amyotrophic lateral sclerosis, interacting with the RNA binding protein TDP-43 [56]. However, it is unknown what the exact role of MATR3 in MATR3-TFE3 fusion of Xp11 translocation renal cell carcinomas is. $F U B P 1$ was first discovered as a transcriptional regulator of the proto-oncogene c-Myc, with important roles in a number of cellular processes including differentiation, cell proliferation, apoptosis, or cell death through the effects of transcription, mRNA stability, and translation [57-59]. $F U B P 1$ is also involved in the apoptosis, proliferation, 
and migration of tumor cells, suggesting that the gene plays an important role in tumor initiation and progression [60-62]. In addition, it has been shown that different TFE3related gene fusions may have different clinicopathologic features of Xp11 translocation renal cell carcinomas. However, our limited clinical data could not yet yield definitive associations of the novel subtypes with clinicopathologic features.

As there is considerable morphological overlap among molecular subtypes of Xp11 translocation renal cell carcinomas and morphologic classification alone can be challenging, we applied multiple methodologies, including FISH, RT-PCR, and RNA sequencing, to provide an accurate classification, and evaluated their abilities to subclassify Xp11 translocation renal cell carcinomas respectively. In clinical practice, immunohistochemical analysis with a TFE3 antibody, as an important means of initial screening, is performed most frequently to support or refute the suspected diagnosis of Xp11 translocation-associated cancers. However, TFE3 immunohistochemistry alone cannot be fully trusted for this diagnosis, which can show false-positive, false-negative, and equivocal results [18, 26]. In this study, we found that 19 of the $22 \mathrm{Xp} 11$ translocationassociated cancers $(86 \%)$ were unequivocally positive for TFE3 by immunohistochemistry, but three were negative or equivocal (14\%). In addition, TFE3 immunohistochemistry cannot provide information as to fusion partner subtype. The TFE3 break-apart FISH assay has proven to be very useful for detecting TFE3 gene rearrangement in Xp11 translocation-associated cancers, often resolving cases in which the morphologic or clinical suspicion is high but TFE3 immunohistochemistry is negative or equivocal. However, recent advances allow being aware that the falsenegative rate of TFE3 FISH has been increasing, as the current TFE3 break-apart probe design could not effectively detect NONO-TFE3, RBM10-TFE3, and GRIPAP1-TFE3 genotypes, all of which involve an inversion of chromosome X [5, 8, 9, 28-30]. We developed a novel MED15TFE3 fusion FISH assay to detect the specific fusion gene. In combination with previously established ASPSCR1TFE3, PRCC-TFE3, SFPQ-TFE3, and NONO-TFE3 fusion FISH probes [5, 7, 30, 44, 49], fusion FISH assays provide a supplementary method to subtyping Xp11 translocation-associated cancers. RT-PCR is a highly specific and objective technique that allows detection of TFE3associated fusion gene transcripts, but it usually requires high-quality RNA (i.e., fresh-frozen samples) and the primers are the genes known to be involved in the gene fusion, which only identifies known fusion variants and reduces sensitivity to detect specific TFE3 fusion partners. In this study, we also applied the latest transcriptome analysis, RNA sequencing, which was a highly sensitive method best suited for unknown gene fusion discovery. It also requires high-quality RNA, although TFE3 fusion transcripts can be detected whatever the fusion partner in both formalin-fixed paraffin-embedded material and fresh frozen samples. Three samples with no identifiable gene fusions in our study were all obtained from old formalin-fixed paraffin-embedded material, although the oldest detectable sample was from 10 years ago. Moreover, this approach has the advantage of a high sensitivity but probably leads to false-positive results, which should be left to those with considerable experience. To validate the results of RNA sequencing, fusion FISH assay is the preferred method than RT-PCR. As each method has its benefits and drawbacks, they can make up each other's limitation when used in combination with multiple methods.

In summary, we provide the first detailed morphologic and immunophenotypic description of the Xp11 translocation renal cell carcinoma with MED15-TFE3 gene fusion. Certain clinicopathologic features have been linked to this specific molecular subtype. In addition to the MED15-TFE3 renal cell carcinoma, we also reported the first case of the corresponding mesenchymal neoplasm with MED15-TFE3 gene fusion. Histologic appearance varied significantly among neoplasms with ASPSCRI-TFE3, PRCC-TFE3, $S F P Q-T F E 3$, and NONO-TFE3 gene fusions, expanding our understanding of morphologic heterogeneity of Xp11 translocation-associated cancers. Furthermore, RNA sequencing identified two novel TFE3 fusion partners, MATR 3 and FUBP1, which broaden the list of TFE3 gene fusion partners. The association between novel TFE3 gene fusions with clinicopathologic features requires further studies. Our study also highlights the importance of combining morphology, immunohistochemistry, and multiple molecular techniques to make an accurate classification of Xp11 translocation-associated cancers.

Acknowledgements The authors thank Nanjing Geneseeq Technology Inc., Nanjing, China, for the NGS service. This work was supported by grants from the National Natural Science Foundation of China (81472391 to Qiu Rao and 81372743 to Xiao-jun Zhou).

\section{Compliance with ethical standards}

Conflict of interest The authors declare that they have no conflict of interest.

\section{References}

1. Argani P, Hawkins A, Griffin CA, et al. A distinctive pediatric renal neoplasm characterized by epithelioid morphology, basement membrane production, focal HMB45 immunoreactivity, and $\mathrm{t}(6 ; 11)(\mathrm{p} 21.1 ; \mathrm{q} 12)$ chromosome translocation. Am J Pathol. 2001;158:2089-96.

2. Argani P, Antonescu CR, Couturier J, et al. PRCC-TFE3 renal carcinomas: morphologic, immunohistochemical, ultrastructural, and molecular analysis of an entity associated with the $t(X ; 1)$ (p11.2; q21). Am J Surg Pathol. 2002;26:1553-66. 
3. Clark J, Lu YJ, Sidhar SK, et al. Fusion of splicing factor genes PSF and NonO (p54nrb) to the TFE3 gene in papillary renal cell carcinoma. Oncogene. 1997;15:2233-9.

4. Calio A, Grignon DJ, Stohr BA, Williamson SR, Eble JN, Cheng L. Renal cell carcinoma with TFE3 translocation and succinate dehydrogenase B mutation. Mod Pathol. 2017;30:407-15.

5. Xia QY, Wang Z, Chen N, et al. Xp11.2 translocation renal cell carcinoma with NONO-TFE3 gene fusion: morphology, prognosis, and potential pitfall in detecting TFE3 gene rearrangement. Mod Pathol. 2017;30:416-26.

6. Pivovarcikova K, Grossmann P, Alaghehbandan R, Sperga M, Michal M, Hes O. TFE3-Fusion Variant Analysis Defines Specific Clinicopathologic Associations Amog Xp11 Translocation Cancers. Am J Surg Pathol. 2017;41:138-40.

7. Argani $\mathrm{P}$, Zhong M, Reuter VE, et al. TFE3-fusion variant analysis defines specific clinicopathologic associations among Xp11 translocation cancers. Am J Surg Pathol. 2016;40:723-37.

8. Argani P, Zhang L, Reuter VE, Tickoo SK, Antonescu CR. RBM10-TFE3 renal cell carcinoma: a potential diagnostic pitfall due to cryptic intrachromosomal Xp11.2 inversion resulting in false-negative TFE3 FISH. Am J Surg Pathol. 2017;41:655-62.

9. Xia QY, Wang XT, Zhan XM, et al. Xp11 translocation renal cell carcinomas (RCCs) with RBM10-TFE3 gene fusion demonstrating melanotic features and overlapping morphology with $\mathrm{t}(6 ; 11)$ RCC: interest and diagnostic pitfall in detecting a paracentric inversion of TFE3. Am J Surg Pathol. 2017;41:663-76.

10. Agaram NP, Sung YS, Zhang L, et al. Dichotomy of genetic abnormalities in PEComas with therapeutic implications. Am J Surg Pathol. 2015;39:813-25.

11. Argani P, Lui MY, Couturier J, Bouvier R, Fournet JC, Ladanyi M. A novel CLTC-TFE3 gene fusion in pediatric renal adenocarcinoma with $t(X ; 17)(p 11.2 ; q 23)$. Oncogene. 2003;22:5374-8.

12. Huang W, Goldfischer M, Babyeva S, et al. Identification of a novel PARP14-TFE3 gene fusion from 10-year-old FFPE tissue by RNA-seq. Genes Chromosomes Cancer. 2015;54:500-5.

13. Malouf GG, Su X, Yao H, et al. Next-generation sequencing of translocation renal cell carcinoma reveals novel RNA splicing partners and frequent mutations of chromatin-remodeling genes. Clin Cancer Res. 2014;20:4129-40.

14. Classe M, Malouf GG, Su X, et al. Incidence, clinicopathological features and fusion transcript landscape of translocation renal cell carcinomas. Histopathology. 2017;70:1089-97.

15. Antic T, Taxy JB, Alikhan M, Segal J. Melanotic translocation renal cell carcinoma with a novel ARID1B-TFE3 gene fusion. Am J Surg Pathol. 2017;41:1576-80.

16. Argani P, Lal P, Hutchinson B, Lui MY, Reuter VE, Ladanyi M. Aberrant nuclear immunoreactivity for TFE3 in neoplasms with TFE3 gene fusions: a sensitive and specific immunohistochemical assay. Am J Surg Pathol. 2003;27:750-61.

17. Argani P. MiT family translocation renal cell carcinoma. Semin Diagn Pathol. 2015;32:103-13.

18. Rao Q, Williamson SR, Zhang S, et al. TFE3 break-apart FISH has a higher sensitivity for Xp11.2 translocation-associated renal cell carcinoma compared with TFE3 or cathepsin $\mathrm{K}$ immunohistochemical staining alone: expanding the morphologic spectrum. Am J Surg Pathol. 2013;37:804-15.

19. Camparo P, Vasiliu V, Molinie V, et al. Renal translocation carcinomas: clinicopathologic, immunohistochemical, and gene expression profiling analysis of 31 cases with a review of the literature. Am J Surg Pathol. 2008;32:656-70.

20. Mosquera JM, Dal Cin P, Mertz KD, et al. Validation of a TFE3 break-apart FISH assay for Xp11.2 translocation renal cell carcinomas. Diagn Mol Pathol. 2011;20:129-37.

21. Kim SH, Choi Y, Jeong HY, Lee K, Chae JY, Moon KC. Usefulness of a break-apart FISH assay in the diagnosis of Xp11.2 translocation renal cell carcinoma. Virchows Arch. 2011; 459:299-306.

22. Klatte T, Streubel B, Wrba F, et al. Renal cell carcinoma associated with transcription factor E3 expression and Xp11.2 translocation: incidence, characteristics, and prognosis. Am J Clin Pathol. 2012;137:761-8.

23. Macher-Goeppinger S, Roth W, Wagener N, et al. Molecular heterogeneity of TFE3 activation in renal cell carcinomas. Mod Pathol. 2012;25:308-15.

24. Martignoni G, Pea M, Gobbo S, et al. Cathepsin-K immunoreactivity distinguishes MiTF/TFE family renal translocation carcinomas from other renal carcinomas. Mod Pathol. 2009; 22:1016-22.

25. Martignoni G, Gobbo S, Camparo P, et al. Differential expression of cathepsin $\mathrm{K}$ in neoplasms harboring TFE3 gene fusions. Mod Pathol. 2011;24:1313-9.

26. Green WM, Yonescu R, Morsberger L, et al. Utilization of a TFE3 break-apart FISH assay in a renal tumor consultation service. Am J Surg Pathol. 2013;37:1150-63.

27. Zhong M, De Angelo P, Osborne L, et al. Dual-color, break-apart FISH assay on paraffin-embedded tissues as an adjunct to diagnosis of Xp11 translocation renal cell carcinoma and alveolar soft part sarcoma. Am J Surg Pathol. 2010;34:757-66.

28. Just PA, Letourneur F, Pouliquen C, et al. Identification by FFPE RNA-Seq of a new recurrent inversion leading to RBM10-TFE3 fusion in renal cell carcinoma with subtle TFE3 break-apart FISH pattern. Genes Chromosomes Cancer. 2016;55:541-8.

29. Wang XT, Xia QY, Zhou XJ, Rao Q. Incidence, clinicopathological features and fusion transcript landscape of translocation renal cell carcinomas. Histopathology. 2017;71:835-6.

30. Wang XT, Xia QY, Ni H, et al. Xp11 neoplasm with melanocytic differentiation of the prostate harbouring the novel NONO-TFE3 gene fusion: report of a unique case expanding the gene fusion spectrum. Histopathology. 2016;69:450-8.

31. Argani P, Aulmann S, Illei PB, et al. A distinctive subset of PEComas harbors TFE3 gene fusions. Am J Surg Pathol. 2010;34:1395-406.

32. Argani P, Aulmann S, Karanjawala Z, Fraser RB, Ladanyi M, Rodriguez MM. Melanotic Xp11 translocation renal cancers: a distinctive neoplasm with overlapping features of PEComa, carcinoma, and melanoma. Am J Surg Pathol. 2009;33:609-19.

33. Tanaka M, Kato K, Gomi K, et al. Perivascular epithelioid cell tumor with SFPQ/PSF-TFE3 gene fusion in a patient with advanced neuroblastoma. Am J Surg Pathol. 2009;33:1416-20.

34. Varinot J, Camparo P, Beurtheret S, Barreda E, Comperat E. An adult case of melanotic Xp11 translocation renal cancers: distinct entity or sub-entity? Int J Surg Pathol. 2011;19:285-9.

35. LeGallo RD, Stelow EB, Sukov WR, Duska LR, Alisanski SB, Folpe AL. Melanoticxp11.2 neoplasm of the ovary: report of a unique case. Am J Surg Pathol. 2012;36:1410-4.

36. Ohe C, Kuroda N, Hes O, et al. A renal epithelioid angiomyolipoma/perivascular epithelioid cell tumor with TFE3 gene break visualized by FISH. Med Mol Morphol. 2012;45:234-7.

37. Lee SE, Choi YL, Cho J, Kim T, Song SY, Sung CO. Ovarian perivascular epithelioid cell tumor not otherwise specified with transcription factor E3 gene rearrangement: a case report and review of the literature. Hum Pathol. 2012;43:1126-30.

38. Williamson SR, Bunde PJ, Montironi R, et al. Malignant perivascular epithelioid cell neoplasm (PEComa) of the urinary bladder with TFE3 gene rearrangement: clinicopathologic, immunohistochemical, and molecular features. Am J Surg Pathol. 2013;37:1619-26.

39. Liu F, Zhang R, Wang ZY, et al. Malignant perivascular epithelioid cell tumor (PEComa) of cervix with TFE3 gene rearrangement: a case report. Int J Clin Exp Pathol. 2014;7:6409-14. 
40. Ritterhouse LL, Cykowski MD, Hassell LA, Slobodov G, Bane BL. Melanotic Xp11 translocation renal cancer: report of a case with a unique intratumoral sarcoid-like reaction. Diagn Pathol. 2014;9:81.

41. Russell CM, Buethe DD, Dickinson S, Sexton WJ. Perivascular epithelioid cell tumor (PEComa) of the urinary bladder associated with Xp11 translocation. Ann Clin Lab Sci. 2014;44:91-98.

42. Shen Q, Rao Q, Xia QY, et al. Perivascular epithelioid cell tumor (PEComa) with TFE3 gene rearrangement: clinicopathological, immunohistochemical, and molecular features. Virchows Arch. 2014;465:607-13.

43. Schoolmeester JK, Dao LN, Sukov WR, et al. TFE3 translocationassociated perivascular epithelioid cell neoplasm (PEComa) of the gynecologic tract: morphology, immunophenotype, differential diagnosis. Am J Surg Pathol. 2015;39:394-404.

44. Rao Q, Shen Q, Xia QY, et al. PSF/SFPQ is a very common gene fusion partner in TFE3 rearrangement-associated perivascular epithelioid cell tumors (PEComas) and melanotic Xp11 translocation renal cancers: clinicopathologic, immunohistochemical, and molecular characteristics suggesting classification as a distinct entity. Am J Surg Pathol. 2015;39:1181-96.

45. Wang XT, Xia QY, Ni H, et al. SFPQ/PSF-TFE3 renal cell carcinoma: a clinicopathologic study emphasizing extended morphology and reviewing the differences between SFPQ-TFE3 RCC and the corresponding mesenchymal neoplasm despite an identical gene fusion. Hum Pathol. 2017;63:190-200.

46. Rao Q, Cheng L, Xia QY, et al. Cathepsin K expression in a wide spectrum of perivascular epithelioid cell neoplasms (PEComas): a clinicopathological study emphasizing extrarenal PEComas. Histopathology. 2013;62:642-50.

47. Xia QY, Wang XT, Ye SB, et al. Novel gene fusion of PRCC-MITF defines a new member of MiT family translocation renal cell carcinoma: clinicopathologic analysis and detection of the gene fusion by RNA-sequencing and FISH. Histopathology 2018;72:786-794.

48. Chang IW, Huang HY, Sung MT. Melanotic Xp11 translocation renal cancer: a case with PSF-TFE3 gene fusion and up-regulation of melanogenetic transcripts. Am J Surg Pathol. 2009;33:1894-901.

49. Wang ZY, Xia QY, Shi SS, et al. Detection of the ASPL-TFE3 and PRCC-TFE3 gene fusion in paraffin-embedded Xp11 translocation renal cell carcinomas. Int $\mathrm{J}$ Clin Exp Pathol. 2016;11:11890-6.
50. Suzigan S, Drut R, Faria P, et al. Xp11 translocation carcinoma of the kidney presenting with multilocular cystic renal cell carcinoma-like features. Int J Surg Pathol. 2007;15:199-203.

51. Argani P, Antonescu CR, Illei PB, et al. Primary renal neoplasms with the ASPL-TFE3 gene fusion of alveolar soft part sarcoma: a distinctive tumor entity previously included among renal cell carcinomas of children and adolescents. Am J Pathol. 2001;159:179-92.

52. Ellis CL, Eble JN, Subhawong AP, et al. Clinical heterogeneity of Xp11 translocation renal cell carcinoma: impact of fusion subtype, age, and stage. Mod Pathol. 2014;27:875-86.

53. Belgrader P, Dey R, Berezney R. Molecular cloning of matrin 3. A 125-kilodalton protein of the nuclear matrix contains an extensive acidic domain. J Biol Chem. 1991;266:9893-9.

54. Erazo A, Goff SP. Nuclear matrix protein Matrin 3 is a regulator of ZAP-mediated retroviral restriction. Retrovirology. 2015;12:57.

55. Zeitz MJ, Malyavantham KS, Seifert B, Berezney R. Matrin 3: chromosomal distribution and protein interactions. J Cell Biochem. 2009;108:125-33.

56. Johnson JO, Pioro EP, Boehringer A, et al. Mutations in the Matrin 3 gene cause familial amyotrophic lateral sclerosis. Nat Neurosci. 2014;17:664-6.

57. Bouchireb N, Clark MS. Human FUSE binding protein 3 gene (FBP3). Map position 9q33-34.1. Chromosome Res. 1999;7:577.

58. de Nigris F, Sica V, Herrmann J, et al. c-Myc oncoprotein: cell cycle-related events and new therapeutic challenges in cancer and cardiovascular diseases. Cell Cycle. 2003;2:325-8.

59. Zhang J, Chen QM. Far upstream element binding protein 1: a commander of transcription, translation and beyond. Oncogene. 2013;32:2907-16.

60. Duncan R, Collins I, Tomonaga T, Zhang T, Levens D. A unique transactivation sequence motif is found in the carboxyl-terminal domain of the single-strand-binding protein FBP. Mol Cell Biol. 1996;16:2274-82.

61. Bazar L, Harris V, Sunitha I, Hartmann D, Avigan M. A transactivator of c-myc is coordinately regulated with the protooncogene during cellular growth. Oncogene. 1995;10:2229-38.

62. Duan J, Bao X, Ma X, et al. Upregulation of far upstream elementbinding protein 1 (FUBP1) promotes tumor proliferation and tumorigenesis of clear cell renal cell carcinoma. PLoS ONE. 2017;12:e169852. 